JGG 2022;70:128-133

doi: 10.36150/2499-6564-N414

\title{
Understanding of frailty amid Japanese elderly people who participated in preventive care events and characteristics of those lacking understanding of frailty
}

\author{
Miki Karasawa1,2, Yuki Tamaura3 ${ }^{3}$ Rie Akamatsu4, Masumi Eda ${ }^{5}$, \\ Himawari Fukasawa ${ }^{5}$, Miki Hokazono ${ }^{5}$, Saya Watanabe², Keiko Fujiwara ${ }^{6}$, \\ Kazuhiro Nishimura ${ }^{6,7}$, Masashi Sakai ${ }^{8}$ \\ ${ }^{1}$ Public Health Section, Toshima City Health and Welfare Division,, Tokyo, Japan; ${ }^{2}$ Former \\ Graduate School of Humanities and Sciences, Ochanomizu University, Tokyo, Japan; ${ }^{3}$ Department \\ of Health and Nutrition, Faculty of Human Life Studies, University of Niigata Prefecture, Niigata, \\ Japan; ${ }^{4}$ Natural Science Division, Faculty of Core Research, Ochanomizu University, Tokyo, Japan; \\ ${ }^{5}$ Graduate School of Humanities and Sciences, Ochanomizu University, Tokyo, Japan; ${ }^{6}$ Department \\ of Nutrition, Ryokufuso Hospital, Tokyo, Japan; ${ }^{7}$ Department of Health and Nutrition Sciences, \\ Faculty of Human Health, Komazawa Women's University, Tokyo, Japan; ${ }^{8}$ Department of Internal \\ Medicine, Ryokufuso Hospital, Tokyo, Japan
}

Background \& aims. In Japan, preventive care events are held at various places. This study examined the understanding of frailty among elderly people who participated in preventive care events and related factors to further demonstrate the effect of frailty prevention in preventive care events.

Methods. A self-administered questionnaire survey was conducted among elderly people who participated in preventive care events in Higashimurayama City, Tokyo, from October to December 2019. We asked about their understanding of frailty, extraversion, variables related to frailty assessment, and demographic characteristics. We analysed 403 participants aged $\geq 65$ years. We examined the degree of understanding of frailty and its related factors.

Results. The responses 'I know of it enough to explain its details' or 'I somewhat know of it' were categorised as 'understanding of frailty ( $n=215,53.4 \%$ )', and the responses 'I have heard of it but do not know its details' or 'I have not heard of it' were categorised as 'non-understanding of frailty $(n=188,46.6 \%)$ '. We found that participants who did not understand frailty were more likely to participate in preventive care events as attendants (odds ratio [95\% confidence interval] $=2.85[1.37$, 5.95]) than participants who understood frailty.

Conclusions. Among elderly people who participated in preventive care events, those who did not understand frailty did not actively participate in community activities. It is necessary to incorporate activities that enable elderly people to recognise their own health conditions and physical functions into community activities.

Key words: extraversion, frailty, participation

di Gerontologia e Geriatria (SIGG)

\section{(c) (1) () (}

\section{OPEN ACCESS}

This is an open access article distributed in accordance with the CC-BY-NC-ND (Creative Commons Attribution-NonCommercial-NoDerivatives 4.0 International) license. The article can be used by giving appropriate credit and mentioning the license, but only for non-commercial purposes and only in the original version. For further information: https://creativecommons.org/licenses/by-nc-nd/4.0/deed.en

\section{INTRODUCTION}

Frailty prevention is meaningful for coping with ageing. Among Japanese elderly people living in the community, physical frailty and pre-frailty have 
an impact on the risk of future disability ${ }^{1}$. One study reported that a decline in the quality of life in Dutch older people is associated with physical, psychological, and social frailty components ${ }^{2}$. Therefore, frailty is important when considering preventive care in elderly people and extension of healthy life expectancy.

In Japan, many preventive care events are held at various places, some of which include frailty in their content ${ }^{3}$. It is necessary to make better use of such events to effectively deal with ageing. Focusing on the people who participate in preventive care events and examining their characteristics may lead to better event content and promote participation by elderly people.

One way to examine the characteristics of those who participate in preventive care events is by analysing the degree of understanding of frailty. Previous studies examining awareness of frailty and its correlates have reported that exercise habits, dietary variety score, social activity, social isolation, and frailty were associated with awareness of frailty ${ }^{4}$. This suggests that many individuals who are aware of frailty are taking good actions to deal with it.

In a previous study, they categorised the responses 'I know the meaning' or 'I have heard of it but do not know the meaning' as awareness of frailty ${ }^{4}$. However, understanding the meaning of words may lead to further frailty countermeasures. Further studies are required to understand the characteristics of those who need to improve their understanding of frailty and to take steps to help improve their understanding of frailty.

It can be inferred that those who participate in preventive care events have a high awareness and understanding of frailty. However, there are still few reports regarding awareness of frailty, and there are no reports targeting participants in preventive care events. It is possible that some of the participants were unaware of it. By understanding the characteristics of those who do not understand frailty, it may be possible to select those individuals who need to focus on intervention in future preventive care events.

One of the characteristics to consider in understanding those who do not understand frailty is extraversion. Previous studies have reported that it contributes to happiness ${ }^{5}$ and mortality ${ }^{6}$ through social participation and lifestyle behaviours, such as leisure activity and social networks. Since extraversion is closely related to social participation, it is necessary to examine the relationship between extraversion and understanding of frailty among those who participate in preventive care events.

Thus, the objective of this study was to examine the degree of understanding of frailty and characteristics of those who did not understand frailty among elderly people who participated in preventive care events to further demonstrate the effect of frailty prevention in preventive care events. Since the relationship between frailty awareness and frailty itself has previously been demonstrated in earlier studies ${ }^{4}$, the examination was omitted in this study.

\section{METHODS}

\section{DESIGN AND PARTICIPANTS}

The present cross-sectional study used data collected from Higashimurayama City (population was 151,296, population ratio of individuals aged $\geq 65$ years was $26.9 \%$ as of March 2021) ${ }^{7}$, in western Tokyo, from October to December 2019. In Higashimurayama City, preventive care events are held once a year in all 13 towns to enable elderly people to live a healthier life. Several towns held events pertaining to frailty. Of the 1,704 participants in the events in 13 towns, 562, who were present at the venue when the questionnaire was distributed, were given an anonymous self-administered questionnaire, and 486 (86.5\%) participants answered it. To examine the understanding of frailty among elderly people, we used data from participants aged $\geq 65$ years $(n=446,79.4 \%$ ) for statistical analysis. The aim of the study was explained to participants, and they were informed that completing the questionnaire implied their consent to participate in the survey. This study was approved by the Ethics Committee of the Ochanomizu University (approval number: 2018-14).

\section{MeAsurements}

\section{Dependent variable}

Understanding of frailty: referring to the question of awareness of frailty in the previous study ${ }^{4}$, understanding of frailty was assessed by asking participants to respond to the following statements: 'I know of it enough to explain its details', 'I somewhat know of it', 'I have heard of it but I do not know its details', and 'I have not heard of it'. We focused on whether participants understood the term of frailty. Therefore, the responses 'I know of it enough to explain its details' or 'I somewhat know of it' were categorised as 'understanding of frailty', and the responses 'I have heard of it but I do not know its details' or 'I have not heard of it' were categorised as 'non-understanding of frailty'.

\section{Independent variable}

Extraversion: participants answered two questions regarding themselves: 'extraverted, enthusiastic' and 'reserved, quiet', refer to the extraversion items of TenItem Personality Inventory ${ }^{8}$. The seven responses were 
from 'I do not really think so' (1 point) to 'I really think so' (7 points). The former item was treated as a reversal item, and the total score of the two items was calculated. A higher score indicated increased extraversion.

\section{Variables related to frailty assessment}

Referring to the questionnaire for elderly people aged $>75$ years ${ }^{9}$, we asked the following four variables related to frailty assessment: body mass index (BMI), participation style in the events (attendant or management staff), members of community groups (yes, no), and self-rated health. BMI was calculated by dividing the weight by the square of the height. With reference to the target BMI range for people aged $\geq 65$ years in Dietary Reference Intakes for Japanese (2020), a BMI of 21.5$24.9 \mathrm{~kg} / \mathrm{m}^{2}$ was classified as normal, a BMl $<21.5 \mathrm{~kg} /$ $\mathrm{m}^{2}$ was classified as underweight, and a $\mathrm{BMl} \geq 25.0$ $\mathrm{kg} / \mathrm{m}^{2}$ was classified as overweight ${ }^{10}$. Regarding community groups, we asked participants to freely describe organisations, such as senior citizens' associations and welfare co-operators, as well as hobby activities. In reference to previous studies ${ }^{11}$, self-rated health was assessed by asking participants to respond to the following statements: 'very good', 'good', 'not good', and 'poor'. We combined the responses 'not good' and 'poor' and classified them as 'poor'.

\section{Demographic characteristics}

Participants provided information on sex, age, and living situation (who they lived with).

\section{Statistical ANALYSIS}

We analysed data from 403 participants who answered the understanding of frailty questionnaire (analysis target $=82.9 \%$ ). First, we confirmed the distribution of understanding of frailty. Participant characteristics were compared between the two groups using the $\chi^{2}$ test. Next, logistic regression analysis was applied to examine the characteristics of those who did not understand frailty adjusting for demographic characteristics and whether the contents of preventive care events that we examined included frailty. In model 1, extraversion; in model 2, variables related to frailty assessment; and in model 3, both were input to independent variables. We used IBM SPSS Statistics 25.0 for Windows (IBM Japan, Ltd., Tokyo, Japan) to conduct our analyses, and the significance level was set at $p<0.05$.

\section{RESULTS}

\section{ChaRACteristics OF PARTICIPANTS}

Of the total 403 participants, 315 were female (78.2\%), the median age was 78 years, 122 participants lived
Table I. Understanding of frailty among participants $(n=403)$.

\begin{tabular}{|l|c|}
\hline & $\mathrm{n}(\%)$ \\
\hline Understanding of frailty & \\
\hline I know of it enough to explain its details & $62(15.4)$ \\
\hline I somewhat know of it & $153(38.0)$ \\
\hline Non-understanding of frailty & \\
\hline I have heard of it but I do not know its details & $88(21.8)$ \\
\hline I have not heard of it & $100(24.8)$ \\
\hline
\end{tabular}

alone (30.3\%), and 150 participants were underweight (37.2\%). In all, 181 people participated in the preventive care events as attendants (44.9\%), and 269 participants were members of community groups (66.7\%). In all, 262 participants had good self-rated health, and 121 participants had high extraversion ( $\geq 9$ points, 30.0\%).

\section{UNDERSTANDING OF FRAILTY}

Table I presents the understanding of frailty among the 403 participants. Sixty-two participants knew frailty well enough to explain its details (15.4\%), 153 participants somewhat knew of it (38.0\%), 88 participants had heard of it but did not know its details (21.8\%), and 100 participants had not heard of it (24.8\%). Therefore, 215 participants understood frailty (53.4\%), and 188 participants did not understand of frailty (46.6\%).

DifFERENCES ACCORDING TO UNDERSTANDING VERSUS NONUNDERSTANDING OF FRAILTY AND THE CHARACTERISTICS OF 'NON-UNDERSTANDING OF FRAILTY' PARTICIPANTS

'Non-understanding of frailty' participants were more likely to participate in preventive care events as attendants $(p=0.001)$, not be members of community groups $(p<0.001)$, and have lower extraversion $(p=0.023)$ than 'understanding of frailty' participants (Tab. II).

\section{Characteristics of 'NON-Understanding OF FRailty' PARTICIPANTS}

In model 1, we found that 'non-understanding of frailty' participants were more likely to have lower extraversion (odds ratio $[95 \%$ confidence interval] $=1.81[1.06$, 3.08]) than 'understanding of frailty' participants. In model 2, we found that 'non-understanding of frailty' participants were more likely to participate in preventive care events as attendants $(2.09[1.14,3.82])$ and not be members of community groups $(2.13$ [1.15, 3.94]) than 'understanding of frailty'. In Model 3 , we found that 'non-understanding of frailty' participants were more likely to participate in preventive care events as attendants $(2.85$ [1.37, 5.95]) than 'understanding of frailty' participants (Tab. III). 
Table II. Participant characteristics by understanding of frailty $(n=403)$.

\begin{tabular}{|c|c|c|c|c|c|}
\hline & & Total & $\begin{array}{l}\text { Understanding } \\
\text { of frailty§ } \\
\text { (n= 215) }\end{array}$ & $\begin{array}{c}\text { Non- } \\
\text { understanding } \\
\text { of frailty } \\
(\mathrm{n}=188)\end{array}$ & $\boldsymbol{P}$ \\
\hline \multicolumn{6}{|l|}{$\operatorname{Sex}^{\dagger}$} \\
\hline & Female & 315 (78.2) & $169(79.7)$ & $146(78.9)$ & 0.901 \\
\hline & Male & $82(20.3)$ & $43(20.3)$ & $39(21.1)$ & \\
\hline \multicolumn{2}{|l|}{ Age (years) ${ }^{\ddagger}$} & $78(73,82)$ & $78(73,82)$ & $78.5(74,83)$ & 0.129 \\
\hline \multicolumn{6}{|c|}{ Living situation ${ }^{\dagger}$} \\
\hline & Living with someone & $274(68.0)$ & $141(66.5)$ & $133(72.3)$ & 0.231 \\
\hline & Living alone & $122(30.3)$ & $71(33.5)$ & $51(27.7)$ & \\
\hline \multicolumn{6}{|l|}{ BMI $\left(\mathbf{k g} / \mathrm{m}^{2}\right)^{\dagger}$} \\
\hline & Underweight $(<21.5)$ & $150(37.2)$ & $84(40.4)$ & $66(39.8)$ & 0.948 \\
\hline & Overweight ( $\geq 25.0$ ) & $65(16.1)$ & $37(17.8)$ & $28(16.9)$ & \\
\hline & Normal (21.5-24.9) & $159(39.5)$ & $87(41.8)$ & $72(43.4)$ & \\
\hline \multicolumn{6}{|c|}{ Participation in events $^{\dagger}$} \\
\hline & Attendant & $181(44.9)$ & $86(51.5)$ & $95(70.9)$ & 0.001 \\
\hline & Management staff & $120(29.8)$ & $81(48.5)$ & $39(29.1)$ & \\
\hline \multicolumn{6}{|c|}{ Member of community groups ${ }^{\dagger}$} \\
\hline & No & $119(29.5)$ & $46(22.1)$ & $73(40.6)$ & $<0.001$ \\
\hline & Yes & $269(66.7)$ & $162(77.9)$ & $107(59.4)$ & \\
\hline \multicolumn{6}{|c|}{ Self-rated health ${ }^{\dagger, \|}$} \\
\hline & Poor & $54(13.4)$ & $23(11.1)$ & $31(16.9)$ & 0.088 \\
\hline & Good & $262(65.0)$ & $138(66.7)$ & $124(67.8)$ & \\
\hline & Very good & $74(18.4)$ & $46(22.0)$ & $28(15.3)$ & \\
\hline \multicolumn{6}{|l|}{ Extraversion $^{\dagger}$} \\
\hline & Low $(<9)$ & $132(32.8)$ & $64(45.7)$ & $68(60.2)$ & 0.023 \\
\hline & High $(\geq 9)$ & $121(30.0)$ & $76(54.3)$ & $45(39.8)$ & \\
\hline
\end{tabular}

${ }^{\dagger} \mathrm{n}(\%)$, Chi-squared test; ${ }^{\ddagger}$ Median $\left(25^{\text {th }}, 75^{\text {th }}\right.$ percentile), Mann-Whitney $U$ test; ${ }^{\S}$ The responses 'I know of it enough to explain its details' or 'I somewhat know of it' were categorised as 'understanding of frailty', and the responses 'I have heard of it but I do not know its details' or 'I have not heard of it' were categorised as 'non-understanding of frailty'; " The responses 'not good' and 'poor' were collectively categorised as poor.

\section{DISCUSSION}

This study examined the understanding of frailty and characteristics of those who did not understand frailty among elderly people who participated in preventive care events. Nearly half of the participants did not understand frailty. Moreover, this study showed that those who did not understand frailty participated in preventive care events as attendants.

In a previous study targeting the elderly people living in a metropolitan area, awareness of frailty, including 'I know the meaning' and 'I have heard of it but do not know the meaning', which has a broader meaning than understanding of frailty in this study, was estimated as $20.1 \%{ }^{4}$. Compared with the aforementioned results, more than half of the participants in this study understood frailty, which was a high value. In the area where this study was conducted, several towns dealt with frailty in preventive care events. A higher understanding of frailty in this study compared with the previous study may have been affected by the continuation of such events. However, nearly half of the participants did not understand frailty, even among the participants of preventive care events. In other general populations, it is inferred that more than half of the population do not understand frailty. Therefore, it is necessary to investigate the understanding of frailty in other areas and to target others and further spread the knowledge of frailty.

Extraversion was no longer relevant to the understanding of frailty when input with variables related to frailty assessment. However, it was significantly associated with an understanding of frailty alone. Extraversion has not been examined in previous studies examining the factors related to frailty awareness ${ }^{4}$. It has been reported that extraversion contributes to mortality through lifestyle behaviours, such as leisure activity and social network ${ }^{6}$. These facts suggest the need for 
Table III. Characteristics of "non-understanding of frailty" participants $(n=403)$

\begin{tabular}{|c|c|c|c|c|c|c|}
\hline & \multicolumn{2}{|c|}{ Model $1^{\dagger}$} & \multicolumn{2}{|c|}{ Model $2^{\ddagger}$} & \multicolumn{2}{|c|}{ Model $3^{\S}$} \\
\hline & OR & $95 \% \mathrm{Cl}$ & OR & $95 \% \mathrm{Cl}$ & OR & $95 \% \mathrm{Cl}$ \\
\hline \multicolumn{7}{|l|}{ Extraversion } \\
\hline Low $(<9)$ & 1.81 & $1.06,3.08$ & - & & 1.61 & $0.83,3.14$ \\
\hline High $(\geq 9)$ & 1 & & & & 1 & \\
\hline \multicolumn{7}{|l|}{ BMI $\left(\mathrm{kg} / \mathrm{m}^{2}\right)$} \\
\hline Underweight $(<21.5)$ & - & & 1.09 & $0.60,2.00$ & 1.06 & $0.50,2.25$ \\
\hline Overweight ( $\geq 25.0$ ) & & & 1.02 & $0.50,2.08$ & 1.24 & $0.52,2.99$ \\
\hline Normal (21.5-24.9) & & & 1 & & 1 & \\
\hline \multicolumn{7}{|c|}{ Participation in events } \\
\hline Attendant & - & & 2.09 & $1.14,3.82$ & 2.85 & $1.37,5.95$ \\
\hline Management staff & & & 1 & & 1 & \\
\hline \multicolumn{7}{|c|}{ Member of community groups } \\
\hline No & - & & 2.13 & $1.15,3.94$ & 1.53 & $0.73,3.22$ \\
\hline Yes & & & 1 & & 1 & \\
\hline \multicolumn{7}{|l|}{ Self-rated health" } \\
\hline Poor & - & & 1.46 & $0.54,3.96$ & 1.28 & $0.39,4.15$ \\
\hline Good & & & 1.24 & $0.61,2.50$ & 0.93 & $0.40,2.16$ \\
\hline Very good & & & 1 & & 1 & \\
\hline
\end{tabular}

Logistic regression analysis was conducted with understanding of frailty as the dependent variable ('non-understanding of frailty' $=1$, 'understanding of frailty' $=0$ ), and adjusting for sex, age, living situation, and whether the contents of preventive care events included frailty.

OR: odds ratio; Cl: confidence interval

${ }^{\dagger}$ Extraversion; ${ }^{\ddagger} \mathrm{BMI}$, participation style in the events, members of community groups, self-rated health; ${ }^{\S}$ Extraversion, BMl, participation style in the events, members of community groups, self-rated health; " The responses 'not good' and 'poor' were collectively categorised as poor.

interventions for people with a low understanding of frailty. In the final model of logistic regression analysis, participation in preventive care events as attendants remained a characteristic of people who did not understand frailty. In model 2, the item 'does not belong to community groups' suggests that they are not active in their community. In the surveyed city, those who participated in the events as management staff thought about what kind of health problems should be publicised in this area when they planned the events with health care workers, social welfare councils, and care managers. Such connections between medical and welfare professionals may help improve the understanding of frailty. As mentioned, different characteristics were observed depending on the understanding of frailty, although the distribution of BMl did not differ between the understanding and non-understanding groups, and approximately $40 \%$ of each group was underweight. Regardless of the degree of understanding, it is necessary not only to provide knowledge of frailty but also to incorporate activities that enable elderly people to recognise their own health condition and physical function. lijima expanded upon 'frailty check' to make elderly people aware of their vulnerability and seriousness of frailty ${ }^{12}$. Elderly people may maintain or improve their physical function by regularly understanding their physical condition.

\section{Limitations}

This study had a limitation. Some items that may be related to the degree of understanding of frailty were not investigated. For example, educational attainment and the number of times of participation in preventive care events may be related to the degree of understanding of frailty.

\section{CONCLUSIONS}

This study demonstrated the understanding of frailty among elderly people who participated in care events. In addition, our study suggests that participants who do not understand frailty were more likely to participate in preventive care events as attendants, to not belong to community groups, and have lower extraversion. It is necessary to incorporate activities that enable elderly people to recognise their own health conditions and physical functions into community activities. The high understanding of frailty among elderly people in this study may be attributed to their participation in preventive care events. Therefore, it is necessary to examine the understanding of frailty among various groups. 


\section{Ethical consideration}

This study was approved by the Ethics Committee of the Ochanomizu University (approval number: 201814).

\section{Acknowledgement}

We would like to thank all the people involved in the preventive care events in Higashimurayama City.

\section{Conflict of interest}

The Authors declare no conflict of interent.

\section{Funding}

This research did not receive any specific grant from funding agencies in the public, commercial, or not-forprofit sectors.

\section{References}

1 Makizako H, Shimada H, Doi T, et al. Impact of physical frailty on disability in community-dwelling older adults: a prospective cohort study. BMJ Open 2015;5:1-9. https:// doi.org/10.1136/bmjopen-2015-008462

2 Gobbens RJJ, van Assen MALM. Associations between multidimensional frailty and quality of life among Dutch older people. Arch Gerontol Geriatr 2017;73:69-76. https:// doi.org/10.1016/j.archger.2017.07.007

3 Ministry of Health, Labour and Welfare, Health and Welfare Bureau for the Elderly, Long-term Care Insurance and Planning Division. Guidance for promoting care prevention through community development (https://www.mhlw.go. jp/stf/seisakunitsuite/bunya/hukushi_kaigo/kaigo_koureisha/yobou/index.html, Accessed 14 April 2020).
4 Seino S, Kitamura A, Tomine $\mathrm{Y}$, et al. Awareness of the term "frailty" and its correlates among older adults living in a metropolitan area, Japanese J Public Heal 2020;67:399412. https://doi.org/10.11236/jph.67.6_399

5 Oerlemans WGM, Bakker AB, Veenhoven R. Finding the key to happy aging: a day reconstruction study of happiness. J Gerontol B Psychol Sci Soc Sci 2011;66:665-674. https://doi.org/10.1093/geronb/gbr040

6 Rizzuto D, Mossello E, Fratiglioni L, et al. Personality and survival in older age: the role of lifestyle behaviors and health status. Am J Geriatr Psychiatry 2017;25:13631372. https://doi.org/10.1016/j.jagp.2017.06.008

7 Higashimurayama City. Demographic table by town and by gender (https://www.city.higashimurayama.tokyo.jp/ kurashi/koseki/matibetunennreibetu.html, Accessed 14 April 2020).

8 Gosling SD, Rentfrow PJ, Swann WB. A very brief measure of the Big-Five personality domains. I Res Pers 2003;37:504-528. https://doi.org/10.1016/ S0092-6566(03)00046-1

9 Ministry of Health, Labour and Welfare. Questionnaire for older adults over 75 years-old (https://www.mhlw.go.jp/ stf/seisakunitsuite/bunya/kenkou_iryou/iryouhoken/hokenjigyou/index_00003.html, Accessed 14 April 2020).

10 Ministry of Health, Labour and Welfare. Dietary reference intakes for Japanese (2020 version) (https://www.mhlw. go.jp/stf/newpage_08517.html, Accessed 14 April 2020).

11 Okado J, Bin A, Tomoyama G, et al. A follow-up study on the relationship between subjective health and mortality among the elderly people. JJHEP 2003;11:31-38. https:// doi.org/10.11260/kenkokyoiku1993.11.31

12 lijima K. Community-dwelling elderly and frailty prevention (including oral frailty). J Japanese Soc Intern Med 2018;107:2469-2477. https://doi.org/10.2169/ naika.107.2469 